\title{
The effect of goal-directed therapy on mortality in patients with sepsis - earlier is better: a meta-analysis of randomized controlled trials
}

\author{
Wan-Jie Gu', Fei Wang ${ }^{2}$, Jan Bakker ${ }^{3}$ Lu Tang ${ }^{2}$ and Jing-Chen Liu ${ }^{{ }^{*}}$
}

\begin{abstract}
Introduction: The Surviving Sepsis Campaign guidelines recommend goal-directed therapy (GDT) for the early resuscitation of patients with sepsis. However, the findings of the ProCESS (Protocolized Care for Early Septic Shock) trial showed no benefit from GDT for reducing mortality rates in early septic shock. We performed a meta-analysis to integrate these findings with existing literature on this topic and evaluate the effect of GDT on mortality due to sepsis.

Methods: We searched the PubMed, Embase and CENTRAL (Cochrane Central Register of Controlled Trials) databases and reference lists of extracted articles. Randomized controlled trials comparing GDT with standard therapy or usual care in patients with sepsis were included. The prespecified primary outcome was overall mortality.

Results: In total, 13 trials involving 2,525 adult patients were included. GDT significantly reduced overall mortality in the random-effects model (relative risk (RR), $0.83 ; 95 \%$ confidence interval $(C \mathrm{C}), 0.71$ to $0.96 ; P=0.01 ; P^{2}=56 \%$ ). Predefined subgroup analysis according to the timing of GDT for resuscitation suggested that a mortality benefit was seen only in the subgroup of early GDT within the first 6 hours (seven trials; RR, $0.77 ; 95 \% \mathrm{Cl}, 0.67$ to $0.89 ; P=0.0004 ; P^{2}=40 \%$ ), but not in the subgroup with late or unclear timing of GDT (six trials; RR, $0.92 ; 95 \% \mathrm{Cl}, 0.69$ to $1.24 ; P=0.59 ; P^{2}=56 \%$ ). GDT was significantly associated with the use of dobutamine (five trials; RR, $2.71 ; 95 \% \mathrm{Cl}, 1.20$ to $6.10 ; P=0.02$ ).

Conclusions: The results of the present meta-analysis suggest that GDT significantly reduces overall mortality in patients with sepsis, especially when initiated early. However, owing to the variable quality of the studies, strong and definitive recommendations cannot be made.
\end{abstract}

\section{Introduction}

Sepsis is a systemic response to infection, which may progress to severe sepsis and septic shock [1]. Severe sepsis and septic shock represent global problems with a high economic burden. In the United States, more than 750,000 people experience severe sepsis each year, with a short-term mortality of $20 \%$ to $30 \%$, reaching up to $50 \%$ when shock is present $[2,3]$. Therefore, numerous therapeutic strategies that aimed at reducing mortality in these patients have been investigated. However, most of them have not led to significant reductions in mortality [4]. Goal-directed therapy (GDT) has been shown to substantially improve clinical outcomes in surgical patients [5]. Two important aspects of a GDT protocol include early

\footnotetext{
* Correspondence: jingchenliu1964@sina.cn

'Department of Anaesthesiology, the First Affiliated Hospital, Guangxi

Medical University, 22 Shuangyong Road, Nanning 530021, China

Full list of author information is available at the end of the article
}

initiation of the therapeutic measures, together with specific (hemodynamic) targets. The Surviving Sepsis Campaign guidelines recommend GDT for the early resuscitation of patients with sepsis [1], which is based largely upon the results of the Rivers et al. trial, in which the researchers reported a 16\% absolute reduction in mortality among patients with severe sepsis or septic shock who received early GDT compared to standard therapy [6]. However, in a recent study, this approach was challenged [7], with no benefit shown when GDT was compared to standard therapy. However, initiating therapy early rather than late in the course of critical illness remains a logical clinical goal. In the context of this situation, we systematically reviewed all trials of GDT in patients with sepsis and performed a meta-analysis, focusing on the early initiation of the protocol and its effect on mortality.

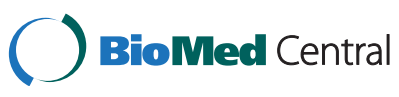

(C) 2014 Gu et al.; licensee BioMed Central Ltd. This is an Open Access article distributed under the terms of the Creative Commons Attribution License (http://creativecommons.org/licenses/by/4.0), which permits unrestricted use, distribution, and reproduction in any medium, provided the original work is properly credited. The Creative Commons Public Domain Dedication waiver (http://creativecommons.org/publicdomain/zero/1.0/) applies to the data made available in this article, unless otherwise stated. 


\section{Methods}

Ethical approval and patient consent were not required, because we conducted a meta-analysis of previously published studies. We followed the recommendations of the Cochrane Handbook for Systematic Reviews of Interventions to carry out the study [8] and follow the PRISMA (Preferred Reporting Items for Systematic Reviews and Meta-Analyses) statement to report our meta-analysis [9].

\section{Search strategy}

Electronic searches were conducted in the PubMed, Embase and Cochrane Central Register of Controlled Trials (CENTRAL) databases. Search terms included "goal directed," "goal oriented," "goal target," "cardiac output," "cardiac index," "oxygen delivery," "oxygen consumption," "cardiac volume," "stroke volume," "fluid therapy," "fluid loading," "fluid administration," "optimization," "optimization," "supranormal" and "sepsis," "severe sepsis," "septic shock," "septicemia," "septicaemia," "pyohemia," "pyaemia" and "pyemia." There was no language restriction placed on the searches. Each database was searched from inception to April 2014. Additionally, reference lists in the articles chosen for inclusion, and the reference lists of previous reviews were screened to identify other potentially eligible trials.

\section{Inclusion criteria}

We included trials with the following characteristics:

1. Population: Adult patients with one or more of the following characteristics were eligible for inclusion: sepsis, severe sepsis or septic shock. Adults were defined as being of a legal age for consent in the country where the trial was conducted. Studies that included sepsis secondary to noninfectious causes were excluded.

2. Intervention: The intervention had to be GDT, defined as an explicit protocol encompassing the use of hemodynamic monitoring and manipulation of hemodynamic parameters to achieve predetermined hemodynamic endpoints.

3. Control: The control group had to have received standard therapy or usual care.

4. Outcomes: The overall mortality rate had to be the outcome measured.

5. Type of study: The studies had to be randomized controlled trials (RCTs).

We included studies that randomized a mixed population of critically ill patients when a septic subpopulation that met our inclusion criteria was defined; that is, the patients with sepsis constituted a subgroup of the trial population.

\section{Data extraction}

We extracted data using a standardized data collection form. Discrepancies in collected data were addressed through team consensus. The following information was extracted from each trial: first author, year of publication, number of patients (GDT and control), study population, clinical setting, goals in GDT and control groups, timing of GDT, mortality endpoint, study design (patient selection and concealment) and outcome data (overall mortality and dobutamine use).

\section{Outcomes and definitions}

The prespecified primary outcome was overall mortality. If the study authors reported mortality at one time point, we used the only data used for analysis. If the study authors reported mortality at more than one time point, we used hospital mortality preferentially. Secondary outcomes included overall mortality in the earlyinitiated GDT (that is, within the first 6 hours) versus GDT and dobutamine use initiated later.

\section{Assessment of risk of bias}

We used the Cochrane Collaboration tool to assess the risk of bias of individual study and with bias domains across studies $[8,10]$. Two investigators (WJG and FW) subjectively reviewed all studies and assigned a value of "high," "low" or "unclear" to the following domains: random sequence generation, allocation concealment, blinding of participants and personnel, blinding of outcome assessment, incomplete outcome data, selective reporting and other bias. Trials with high risk of bias for any one or more key domains were considered to be at high risk of bias. Trials with low risk of bias for all key domains were considered to be at low risk of bias. Otherwise, they were considered to have an unclear risk of bias [10].

\section{Statistical analysis}

We estimated the relative risk (RR) with 95\% confidence interval (CI) for dichotomous outcomes. Statistical heterogeneity across studies was tested by using the $I^{2}$ statistic $[11,12]$. Heterogeneity was suggested if the $P$-value was $\leq 0.10$. $I^{2}$ values of 0 to $24.9 \%, 25 \%$ to $49.9 \%, 50 \%$ to $74.9 \%$ and $75 \%$ to $100 \%$ were considered zero, low, moderate and high thresholds for statistical heterogeneity, respectively $[11,12]$. Clinical heterogeneity could not be excluded, so the more conservative random-effects model [13] (MantelHaenszel method) was used. Predefined subgroup analysis was conducted according to the timing of GDT for resuscitation (early being within the first 6 hours versus late or unclear being outside the first 6 hours or unclear timing). In addition, we performed post hoc subgroup analyses according to risk of bias (low versus unclear), sample size $(\geq 100$ versus <100) and setting (emergency department versus 
intensive care unit). We further investigated the influence of a single study on the overall pooled estimate by omitting one study in each step. The potential for bias was assessed by inspection of a funnel plot and Egger's test [14]. The results were considered statistically significant at two-sided $P$-values $<0.05$. All statistical analyses were performed using RevMan 5.2 software (The Nordic Cochrane Centre, Copenhagen, Denmark).

\section{Quality of evidence}

We evaluated the quality of the evidence by using the Grades of Recommendation, Assessment, Development and Evaluation (GRADE) approach [15]. In addition, the GRADEprofiler 3.6 software (The Nordic Cochrane Centre) was used to create the evidence profile. The GRADE Working Group grades of evidence used were as follows:

(1)High quality: Further research is very unlikely to change our confidence in the estimate of effect.

(2)Moderate quality: Further research is likely to have an important impact on our confidence in the estimate of effect and may change the estimate.

(3) Low quality: Further research is very likely to have an important impact on our confidence in the estimate of effect and is likely to change the estimate.
(4) Very low quality: We are very uncertain about the estimate.

\section{Results}

In the initial search, we identified 1,263 records. After examination of the titles and abstracts, there were 30 potentially eligible studies assessed for inclusion. After application of the inclusion criteria, 13 RCTs $[6,7,16-26]$ were included in the meta-analysis. The study flow diagram, including the reasons for exclusion of studies, is shown in Figure 1.

\section{Study characteristics}

The characteristics of the included trials are presented in Table 1. These trials were published between 1992 and 2014. The sample size of the trials ranged from 34 to 895 , with a total of 2,525 patients comprising 1,299 in the GDT group and 1,226 in the control group. Eleven trials were conducted in the intensive care unit [16-26], and the remaining two were conducted in the emergency department [6,7]. Four trials were published in Chinese [23-26], and the other nine trials were in English [6,7,16-22]. Early GDT for resuscitation within the first 6 hours was reported in seven trials $[6,7,16,21,22,24-26]$, late GDT for resuscitation outside the first 6 hours was assessed in one trial [23] and unclear timing of GDT was described in five trials [17-21]. Overall mortality was reported in all trials

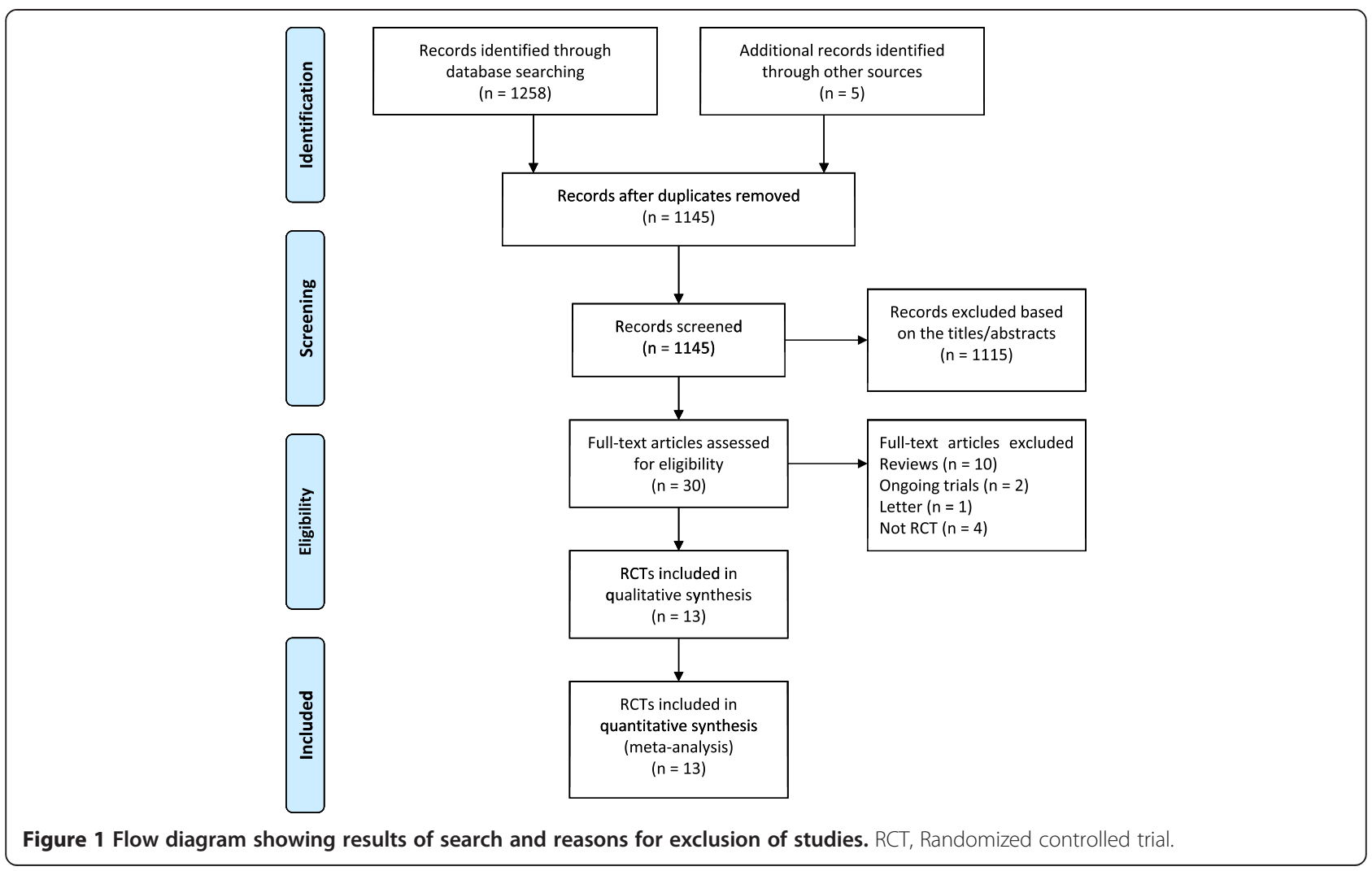


Table 1 Characteristics of included randomized controlled trials ${ }^{a}$

\begin{tabular}{|c|c|c|c|c|c|c|c|c|}
\hline Study & Year & $\begin{array}{l}\text { No. of patients with } \\
\text { sepsis (GDT/control) }\end{array}$ & Study population & $\begin{array}{l}\text { Clinical } \\
\text { setting }\end{array}$ & Goals in GDT group & Goals in control group & $\begin{array}{l}\text { Timing of } \\
\text { GDT }\end{array}$ & $\begin{array}{l}\text { Mortality } \\
\text { endpoint }\end{array}$ \\
\hline \multirow[t]{2}{*}{ Tuchschmidt et al. [16] } & \multirow[t]{2}{*}{1992} & \multirow[t]{2}{*}{$51(26 / 25)$} & \multirow[t]{2}{*}{ Adult patients with septic shock } & \multirow[t]{2}{*}{ ICU } & $\mathrm{Cl} \geq 6 \mathrm{~L} / \mathrm{min} / \mathrm{m}^{2}$ & $\mathrm{Cl} \geq 3 \mathrm{~L} / \mathrm{min} / \mathrm{m}^{2}$ & \multirow{2}{*}{$\begin{array}{l}\text { Within the } \\
\text { first } 6 \mathrm{hr}\end{array}$} & \multirow[t]{2}{*}{14 days } \\
\hline & & & & & $\mathrm{SBP} \geq 90 \mathrm{mmHg}$ & $\mathrm{SBP} \geq 90 \mathrm{mmHg}$ & & \\
\hline \multirow[t]{2}{*}{ Yu et al. [17] } & \multirow[t]{2}{*}{1993} & \multirow[t]{2}{*}{$52(30 / 22)$} & $\begin{array}{l}\text { Adult patients with sepsis or septic } \\
\text { shock }\end{array}$ & \multirow[t]{2}{*}{ ICU } & $\mathrm{DO}_{2} \mathrm{I}>600 \mathrm{ml} / \mathrm{min} / \mathrm{m}^{2}$ & $\mathrm{DO}_{2} \mid 450$ to $550 \mathrm{ml} / \mathrm{min} / \mathrm{m}^{2}$ & \multirow[t]{2}{*}{ Unclear } & \multirow[t]{2}{*}{30 days } \\
\hline & & & (septic subpopulation) & & $\mathrm{SBP}>100 \mathrm{mmHg}$ & $\mathrm{SBP}>100 \mathrm{mmHg}$ & & \\
\hline \multirow[t]{3}{*}{ Hayes et al. [18] } & \multirow[t]{3}{*}{1994} & \multirow[t]{3}{*}{$47(24 / 23)$} & Adult patients with septic shock & \multirow[t]{3}{*}{ ICU } & $\mathrm{Cl} \geq 4.5 \mathrm{~L} / \mathrm{min} / \mathrm{m}^{2}$ & Usual care & \multirow[t]{3}{*}{ Unclear } & \multirow[t]{3}{*}{ Hospital } \\
\hline & & & \multirow[t]{2}{*}{ (septic subpopulation) } & & \multirow{2}{*}{\multicolumn{2}{|c|}{$\begin{array}{l}\mathrm{DO}_{2} 600 \mathrm{ml} / \mathrm{min} / \mathrm{m}^{2} \\
\mathrm{VO}_{2}>170 \mathrm{ml} / \mathrm{min} / \mathrm{m}^{2}\end{array}$}} & & \\
\hline & & & & & & & & \\
\hline \multirow[t]{5}{*}{ Gattinoni et al. [19] } & \multirow[t]{5}{*}{1995} & \multirow[t]{5}{*}{$181(124 / 57)$} & \multirow{2}{*}{$\begin{array}{l}\text { Adult patients with septic shock or } \\
\text { septic syndrome }\end{array}$} & \multirow[t]{5}{*}{ ICU } & $\mathrm{Cl} \geq 4.5 \mathrm{~L} / \mathrm{min} / \mathrm{m}^{2}$ or & $\mathrm{Cl} 2.5$ to $3.5 \mathrm{~L} / \mathrm{min} / \mathrm{m}^{2}$ & \multirow[t]{5}{*}{ Unclear } & \multirow[t]{5}{*}{ ICU } \\
\hline & & & & & $\mathrm{SVO}_{2} \geq 10 \%$ & MAP $\geq 65 \mathrm{mmHg}$ & & \\
\hline & & & \multirow[t]{3}{*}{ (septic subpopulation) } & & MAP $\geq 65 \mathrm{mmHg}$ & CVP 8 to $12 \mathrm{mmHg}$ & & \\
\hline & & & & & CVP 8 to $12 \mathrm{mmHg}$ & $\cup O \geq 0.5 \mathrm{ml} / \mathrm{kg} / \mathrm{hr}$ & & \\
\hline & & & & & $\cup O \geq 0.5 \mathrm{ml} / \mathrm{kg} / \mathrm{h}$ & & & \\
\hline \multirow[t]{4}{*}{ Yu et al. [20] } & 1998 & $87(58 / 29)$ & Adult patients with sepsis, severe & $\mathrm{ICU}$ & $\mathrm{DO}_{2} \mathrm{l}>600 \mathrm{ml} / \mathrm{min} / \mathrm{m}^{2}$ & $\mathrm{DO}_{2} \mathrm{l} 450$ to $550 \mathrm{ml} / \mathrm{min} / \mathrm{m}^{2}$ & Unclear & $\mathrm{ICU}$ \\
\hline & & & sepsis or septic snock & & $\mathrm{SBP} \geq 100 \mathrm{mmHg}$ & $\mathrm{SBP} \geq 100 \mathrm{mmHg}$ & & \\
\hline & & & (septic subpopulation) & & $\mathrm{SvO}_{2}>65 \%$ & $\mathrm{SvO}_{2}>65 \%$ & & \\
\hline & & & & & UO $>50 \mathrm{ml} / \mathrm{hr}$ & UO $>50 \mathrm{ml} / \mathrm{hr}$ & & \\
\hline Alía et al. [21] & 1999 & $63(31 / 32)$ & Adult patients with severe sepsis or & ICU & $\mathrm{DO}_{2} \mathrm{l}>600 \mathrm{ml} / \mathrm{min} / \mathrm{m}^{2}$ & $\mathrm{DO}_{2} 1>330 \mathrm{ml} / \mathrm{min} / \mathrm{m}^{2}$ & Unclear & $\mathrm{ICU}$ \\
\hline & & & & & MAP $>60 \mathrm{mmHg}$ & MAP $>60 \mathrm{mmHg}$ & & \\
\hline Rivers et al. [6] & 2001 & $263(130 / 133)$ & Adult patients with severe sepsis, & ED & $\mathrm{SvO}_{2} \geq 70 \%$ & CVP 8 to $12 \mathrm{mmHg}$ & Within the & Hospital \\
\hline & & & & & CVP 8 to $12 \mathrm{mmHg}$ & MAP 65 to $90 \mathrm{mmHg}$ & & \\
\hline & & & & & MAP 65 to $90 \mathrm{mmHg}$ & $\cup O \geq 0.5 \mathrm{ml} / \mathrm{kg} / \mathrm{hr}$ & & \\
\hline & & & & & $\cup O \geq 0.5 \mathrm{ml} / \mathrm{kg} / \mathrm{hr}$ & & & \\
\hline Lin et al. [22] & 2006 & $224(108 / 116)$ & Adult patients with septic shock & $\mathrm{ICU}$ & CVP 8 to $12 \mathrm{mmHg}$ & Usual care & Within the & Hospital \\
\hline & & & & & MAP $\geq 65 \mathrm{mmHg}$ & & & \\
\hline & & & & & $\cup O \geq 0.5 \mathrm{ml} / \mathrm{kg} / \mathrm{hr}$ & & & \\
\hline Wang et al. [23] & 2006 & $34(16 / 17)$ & Adult patients with septic shock & $\mathrm{ICU}$ & $\mathrm{SvO}_{2} \geq 70 \%$ & MAP $\geq 65 \mathrm{mmHg}$ & Within the & 14 days \\
\hline & & & & & CVP 8 to $12 \mathrm{mmHg}$ & $\cup O \geq 0.5 \mathrm{ml} / \mathrm{kg} / \mathrm{hr}$ & $\begin{array}{l}\text { first } 6 \text { to } \\
10 \mathrm{hr}\end{array}$ & \\
\hline & & & & & $\mathrm{MAP} \geq 65 \mathrm{mmHg}$ & & & \\
\hline & & & & & $\cup O \geq 0.5 \mathrm{ml} / \mathrm{kg} / \mathrm{hr}$ & & & \\
\hline
\end{tabular}


Table 1 Characteristics of included randomized controlled trials ${ }^{\mathrm{a}}$ (Continued)

\begin{tabular}{|c|c|c|c|c|c|c|c|c|}
\hline \multirow[t]{4}{*}{ Chen et al. [24] } & \multirow[t]{4}{*}{2007} & \multirow[t]{4}{*}{$123(58 / 65)$} & Adult patients with severe sepsis & \multirow[t]{4}{*}{ ICU } & $\mathrm{ScvO}_{2} \geq 70 \%$ & CVP 8 to $12 \mathrm{mmHg}$ & \multirow{4}{*}{$\begin{array}{l}\text { Within the } \\
\text { first } 6 \mathrm{hr}\end{array}$} & \multirow[t]{4}{*}{ ICU } \\
\hline & & & \multirow[t]{3}{*}{ (septic subpopulation) } & & CVP 8 to $12 \mathrm{mmHg}$ & MAP $\geq 65 \mathrm{mmHg}$ & & \\
\hline & & & & & MAP $\geq 65 \mathrm{mmHg}$ & $\mathrm{UO} \geq 0.5 \mathrm{ml} / \mathrm{kg} / \mathrm{hr}$ & & \\
\hline & & & & & $\cup O \geq 0.5 \mathrm{ml} / \mathrm{kg} / \mathrm{hr}$ & & & \\
\hline \multirow[t]{4}{*}{ He et al. [25] } & \multirow[t]{4}{*}{2007} & \multirow[t]{4}{*}{$203(98 / 105)$} & \multirow[t]{4}{*}{ Adult patients with septic shock } & \multirow[t]{4}{*}{ ICU } & $\mathrm{ScvO}_{2}$ or $\mathrm{SvO}_{2} \geq 70 \%$ & Usual care & \multirow{4}{*}{$\begin{array}{l}\text { Within the } \\
\text { first } 6 \mathrm{hr}\end{array}$} & \multirow[t]{4}{*}{ Hospital } \\
\hline & & & & & CVP 8 to $12 \mathrm{mmHg}$ & & & \\
\hline & & & & & MAP $\geq 65 \mathrm{mmHg}$ & & & \\
\hline & & & & & $\cup O \geq 0.5 \mathrm{ml} / \mathrm{kg} / \mathrm{hr}$ & & & \\
\hline \multirow[t]{5}{*}{ Yan et al. [26] } & \multirow[t]{5}{*}{2010} & \multirow[t]{5}{*}{$303(157 / 146)$} & \multirow{5}{*}{$\begin{array}{l}\text { Adult patients with severe sepsis or } \\
\text { septic shock }\end{array}$} & \multirow[t]{5}{*}{ ICU } & $\mathrm{ScvO}_{2} \geq 70 \%$ & CVP 8 to $12 \mathrm{mmHg}$ & \multirow{5}{*}{$\begin{array}{l}\text { Within the } \\
\text { first } 6 \mathrm{hr}\end{array}$} & \multirow[t]{5}{*}{$\mathrm{ICU}$} \\
\hline & & & & & CVP 8 to $12 \mathrm{mmHg}$ & $\mathrm{SBP}>90 \mathrm{mmHg}$ & & \\
\hline & & & & & $\mathrm{SBP}>90 \mathrm{mmHg}$ & MAP $\geq 65 \mathrm{mmHg}$ & & \\
\hline & & & & & MAP $\geq 65 \mathrm{mmHg}$ & $\cup O \geq 0.5 \mathrm{ml} / \mathrm{kg} / \mathrm{hr}$ & & \\
\hline & & & & & $\mathrm{UO} \geq 0.5 \mathrm{ml} / \mathrm{kg} / \mathrm{hr}$ & & & \\
\hline \multirow[t]{4}{*}{ ProCESS [7] } & \multirow[t]{4}{*}{2014} & \multirow[t]{4}{*}{$895(439 / 456)$} & \multirow[t]{4}{*}{ Adult patients with septic shock } & \multirow[t]{4}{*}{ ED } & $\mathrm{ScvO}_{2} \geq 70 \%$ & Usual care & \multirow{4}{*}{$\begin{array}{l}\text { Within the } \\
\text { first } 6 \mathrm{hr}\end{array}$} & \multirow[t]{4}{*}{ Hospital } \\
\hline & & & & & CVP 8 to $12 \mathrm{mmHg}$ & & & \\
\hline & & & & & MAP 65 to $90 \mathrm{mmHg}$ & & & \\
\hline & & & & & $\mathrm{UO} \geq 0.5 \mathrm{ml} / \mathrm{kg} / \mathrm{hr}$ & & & \\
\hline
\end{tabular}

$\cup O \geq 0.5 \mathrm{ml} / \mathrm{kg} / \mathrm{hr}$

${ }^{a} \mathrm{Cl}$, Cardiac index; CVP, Central venous pressure; $\mathrm{DO}_{2}$, Oxygen delivery; $\mathrm{DO}_{2} \mathrm{l}$, Oxygen delivery index; ED, Emergency department; GDT, Goal-directed therapy; ICU, Intensive care unit; MAP, Mean arterial pressure; ProCESS, Protocolized Care for Early Septic Shock; SIRS, Systemic inflammatory response syndrome; SBP, Systolic blood pressure; $\mathrm{ScvO}_{2}$, Central venous oxygen saturation; $\mathrm{SvO}_{2}$, Mixed venous oxygen saturation; UO, Urine output; $\mathrm{VO}_{2}$, Oxygen consumption. 
[6,7,16-26], and dobutamine use was described in eight of them $[6,7,16-19,21,22]$.

\section{Risk of bias in included studies}

The details of risk of bias are summarized in Figure 2. Five trials were judged to be at low risk of bias $[6,7,19,21,22]$, and eight trials were judged to be at unclear risk of bias [16-18,20,23-26]. Adequate randomized sequences were generated in eight trials $[6,7,17-19,21,22,26]$, and the investigators in five trials reported appropriate allocation concealment $[6,7,19,21,22]$. Among the 13 RCTs, none were doubleblinded. However, blinding of patients and clinicians was extremely difficult in these trials to evaluate a complex intervention such as a GDT protocol, and we judged that the primary outcome (that is, overall mortality) was not likely to be influenced by lack of blinding.

\section{Primary outcome: overall mortality}

Mortality data were available in all 13 included trials $[6,7,16-26]$. The overall mortality data in the GDT and control groups were 474 (36.5\%) of 1,299 and 520 (42.4\%) of 1,226 , respectively. Overall, GDT significantly reduced overall mortality in the random-effects model (RR, 0.83; 95\% CI, 0.71 to $0.96 ; P=0.01 ; I^{2}=56 \%$ ) (Figure 3). Further exclusion of any single study did not alter the overall combined RR, which ranged from 0.80 (95\% CI, 0.69 to 0.93 ) to 0.85 ( $95 \% \mathrm{CI}, 0.73$ to 0.98 ). The results of subgroup analyses are presented in Table 2.

\section{Secondary outcomes}

Predefined subgroup analysis according to the timing of GDT for resuscitation suggested that a mortality benefit was seen only in the subgroup in early GDT within the first 6 hours (seven trials; RR, 0.77; 95\% CI, 0.67 to 0.89 ; $P=0.0004 ; I^{2}=40 \%$ ) (Figure 4), but not in the subgroup with late or unclear timing of GDT (six trials; RR, 0.92; 95\% CI, 0.69 to $1.24 ; P=0.59 ; I^{2}=56 \%$ ) (Figure 4 ).

In five trials, the investigators reported available data on dobutamine use $[6,7,16,21,22]$. In those trials, GDT was significantly associated with dobutamine use (RR, 2.71; $95 \%$ CI, 1.20 to $6.10 ; P=0.02 ; I^{2}=86 \%$ ).

\section{Publication bias}

We detected no evidence of publication bias by assessing funnel plot either visually (Figure 5 ) or statistically $(P=0.367$ by Egger test).

\section{GRADE profile evidence}

We found that GRADE Working Group grades of evidence were low for overall mortality, moderate for mortality in early GDT (within the first 6 hours for resuscitation)

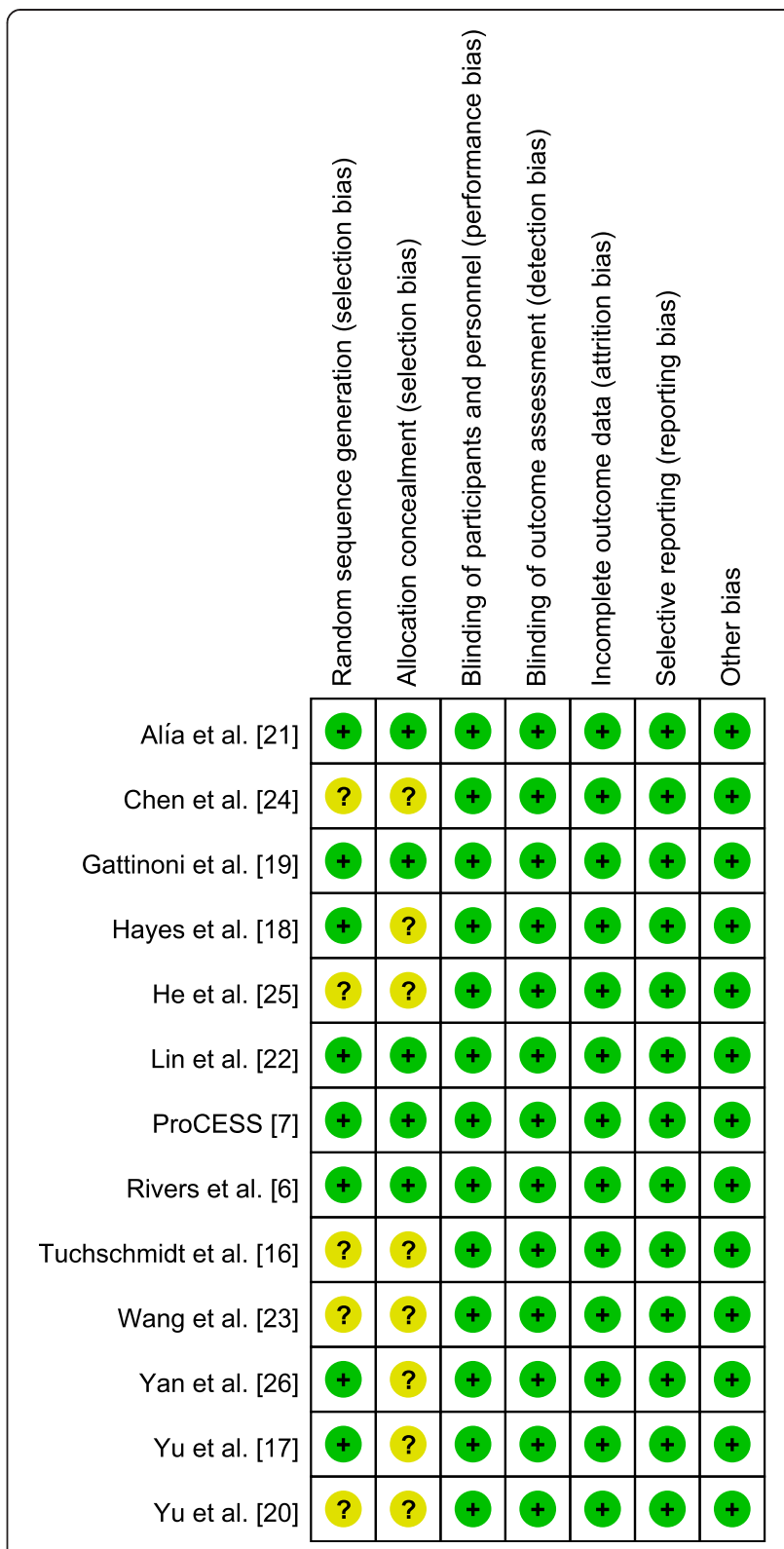

Figure 2 Risk of bias summary.

and very low for dobutamine use. An additional doc file shows these data in more detail (see Additional file 1).

\section{Discussion}

Our meta-analysis of 13 RCTs showed that GDT was associated with a $17 \%$ RR reduction on overall mortality in patients with sepsis. This mortality benefit was present in studies in which GDT was started early, but not when initiated late or when the timing of GDT was unclear. In addition, GDT was significantly associated with dobutamine use.

Despite these findings, the effect of GDT remains a matter of debate, as the most recent and largest trial 
included in this meta-analysis [7] did not show a difference in mortality, in contrast to many of the preceding studies. This could be due to the effect of the rapid acceptance of the principal interventions of the Rivers et al. study [6] and the subsequent Surviving Sepsis Campaign guidelines, which encompassed all elements of the Rivers study protocol. This is illustrated by the fact that, in the ProCESS (Protocolized Care for Early Septic Shock) trial, all groups received, on average, more than $2 \mathrm{~L}$ of fluid prior to randomization and more than $75 \%$ of patients received antibiotics before randomization. In addition, the mortality rate was much lower in the ProCESS trial than in preceding trials, possibly reflecting the effect of early diagnosis, fluid resuscitation and initiation of antibiotics on mortality. As the ProCESS trial, like the Rivers et al. study, enrolled patients with sepsis in the emergency department, this effect may have been prominent [27].

Although the current evidence supports the early use of GDT to improve outcomes in patients with sepsis, the optimal goals remain uncertain. Currently, the Surviving Sepsis Campaign guidelines recommend the use of central venous pressure (CVP), mean arterial pressure, urine output and central venous oxygen saturation $\left(\mathrm{ScrO}_{2}\right)$ as resuscitation goals. However, many of these recommendations have been questioned in recent studies. A recent study [28] was designed to compare the use of lactate clearance to $\mathrm{ScvO}_{2}$ as a goal of early (up to 6 hours) sepsis resuscitation. No significant difference in mortality was found (17\% in the lactate clearance group versus $23 \%$ in $\mathrm{ScvO}_{2}$ group). However, when both normalization of $\mathrm{ScvO}_{2}$ and a rapid decrease in lactate levels were applied as therapeutic goals in the early resuscitation of a mixed group of critically ill patients, including a large subgroup of sepsis patients, mortality was significantly reduced [29]. In addition, in a recent retrospective study, researchers questioned the CVP endpoint in sepsis resuscitation [30].

Further research is needed before strong and definitive recommendations can be made regarding the effect of

Table 2 Subgroup analyses of overall mortality ${ }^{a}$

\begin{tabular}{|c|c|c|c|c|c|}
\hline Subgroups & No. of studies & No. of patients & RR $(95 \% \mathrm{Cl})$ & $P$-value & $I^{2}(\%)$ \\
\hline All trials $[6,7,16-26]$ & 13 & 2,525 & 0.83 (0.71 to 0.96) & 0.01 & 56 \\
\hline \multicolumn{6}{|l|}{ GDT timing } \\
\hline Early $[6,7,16,22,24-26]$ & 7 & 2,062 & 0.77 (0.67 to 0.89) & 0.0004 & 40 \\
\hline Late or unclear $[17-21,23]$ & 6 & 463 & 0.92 (0.69 to 1.24$)$ & 0.59 & 56 \\
\hline \multicolumn{6}{|l|}{ Risk of bias } \\
\hline $\operatorname{Low}[6,7,19,21,22]$ & 5 & 1,626 & 0.92 (0.75 to 1.13$)$ & 0.42 & 67 \\
\hline Unclear [16-18,20,23-26] & 8 & 899 & 0.74 (0.62 to 0.89 ) & 0.002 & 31 \\
\hline \multicolumn{6}{|l|}{ Sample size } \\
\hline$\geq 100[6,7,19,22,24-26]$ & 7 & 2,192 & 0.82 (0.70 to 0.95$)$ & 0.01 & 59 \\
\hline$<100[16-18,20,21,23]$ & 6 & 333 & $0.81(0.56$ to 1.17$)$ & 0.27 & 61 \\
\hline \multicolumn{6}{|l|}{ Setting } \\
\hline $\mathrm{ED}[6,7]$ & 2 & 1,158 & 0.86 (0.52 to 1.44$)$ & 0.52 & 83 \\
\hline ICU [16-26] & 11 & 1,367 & 0.81 (0.69 to 0.96$)$ & 0.01 & 53 \\
\hline
\end{tabular}

${ }^{a} \mathrm{Cl}$, Confidence interval; ED, Emergency department; GDT, Goal-directed therapy; ICU, Intensive care medicine; RR, Relative risk. 
GDT for resuscitation of patients with sepsis. There are currently at least two ongoing RCTs of GDT in patients with sepsis: the Australasian Resuscitation in Sepsis Evaluation (ARISE) trial in Australia (ClinicalTrials.gov ID: NCT00975793) and the Protocolised Management in Sepsis (ProMISe) trial in the United Kingdom (Current Controlled Trials number: ISRCTN36307479) [31]. The results of these ongoing trials should provide further guidance as to the effect of GDT for resuscitation of patients with sepsis.
A major strength of the present meta-analysis is its compliance with the Cochrane handbook methodology recommendations. We conducted an exhaustive literature search that included non-English-language articles. Two authors independently screened all references, included eligible trials, extracted data information, assessed risk of bias and performed statistical analyses. Moreover, we followed the PRISMA statement to report this metaanalysis and evaluated the quality of the evidence by using the GRADE approach.

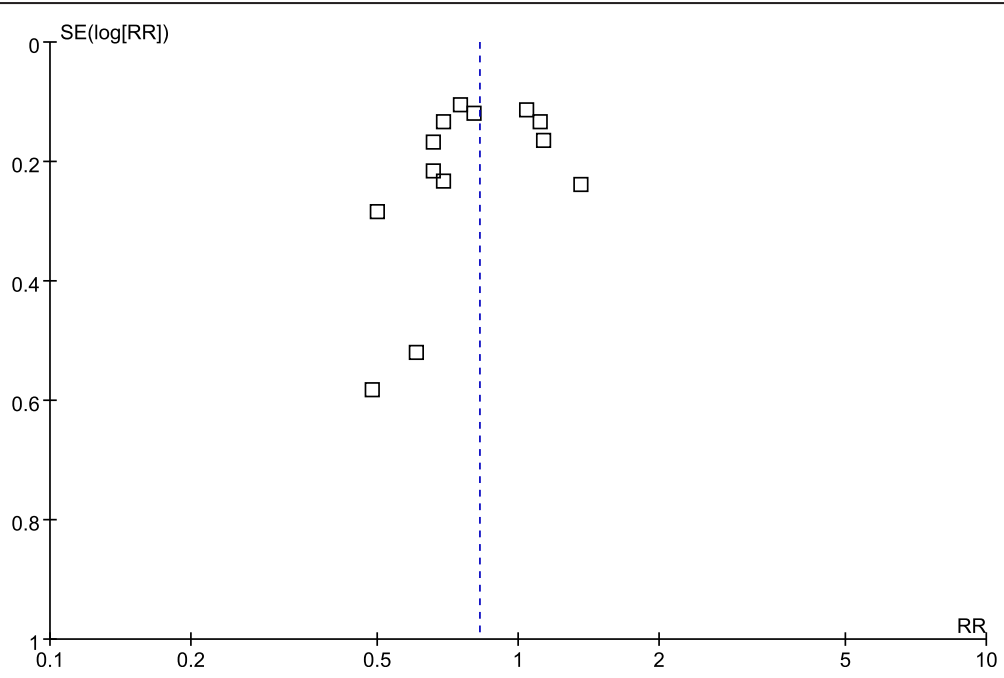

Figure 5 Funnel plot of the effect goal-directed therapy on overall mortality. GDT, Goal-directed therapy. 
Because early fluid resuscitation is vital in patients with sepsis, we performed predefined subgroup analyses according to the timing of GDT. We also performed post hoc subgroup analyses according to risk of bias, disease severity, sample size and publication date. These subgroup analyses based on assessment of bias and clinically relevant groups may help health care professionals in clinical decision-making.

Our analysis also has several limitations that must be taken into consideration when interpreting the results. First, most of the included trials had a high risk of bias (Figure 2). The potential importance of this issue is highlighted by the fact that predefined subgroup analysis comparing mortality estimates between trials with low versus unclear risk of bias suggested the mortality benefit is not clearly apparent among the trials with low risk of bias, although this subgroup difference was not statistically significant $(P=0.90)$. Second, there were some differences in the target populations and protocols of GDT of each study. These factors may have a potential impact on our results and may preclude firm conclusions. Third, different endpoints were used for mortality evaluation. Because this study was a study-level meta-analysis, individual patient data were not included in the analysis; thus, we could not adjust for patient-level confounders.

\section{Conclusions}

The evidence suggests that GDT significantly reduces overall mortality in patients with sepsis, especially when initiated early (within the first 6 hours of admission). Until the results of ongoing randomized controlled trials are known, strong and definitive recommendations cannot be made regarding the effect of GDT for resuscitation of patients with sepsis.

\section{Key messages}

- The Surviving Sepsis Campaign guidelines recommend GDT for the early resuscitation of patients with sepsis, but controversies about its effect remain.

- The recent ProCESS trial has shown no mortality benefit from GDT in early septic shock.

- The current evidence, in the aggregate, suggests that GDT significantly reduces overall mortality in patients with sepsis, especially when initiated early (within the first 6 hours of admission).

- Further research is needed before strong and definitive recommendations can be made regarding the effect of GDT for resuscitation of patients with sepsis, and the optimal goals remain uncertain.

\section{Additional file}

Additional file 1: GRADE summary of findings.

\section{Abbreviations}

ARISE: Australasian Resuscitation in Sepsis Evaluation; Cl: Confidence interval; CVP: Central venous pressure; GDT: Goal-directed therapy; GRADE: Grades of Recommendation, Assessment, Development and Evaluation; MAP: Mean arterial pressure; PRISMA: Preferred reporting items for systematic reviews and meta-analyses; ProMISe: Protocolised management in sepsis;

RCT: Randomized controlled trial; RR: Relative risk; $\mathrm{SCvO}_{2}$ : Central venous oxygen saturation.

\section{Competing interests}

The authors declare that they have no competing interests.

\section{Authors' contributions}

WJG conceived of the study, participated in its design, collected the data, performed statistical analyses and drafted the manuscript. FW collected the data, performed statistical analyses and helped to draft the manuscript. JB participated in the study design, collected the data and helped to revise the manuscript critically for important intellectual content. LT collected the data, performed statistical analyses and helped to revise the manuscript critically for important intellectual content. JCL conceived of the study, participated in its design, collected the data and revised the manuscript critically for important intellectual content. All authors read and approved the final manuscript.

\section{Authors' details}

WJG is now studying as a master course student and majors in anesthesiology. His major research interests include systematic reviews and meta-analysis, evidence-based medicine, critical care medicine and clinical anesthesiology. As the first author, he has published more than 20 papers in peer-reviewed journals such as Chest, European Respiratory Journal, Critical Care Medicine, Intensive Care Medicine and Critical Care. He has authored chapters of a book on his research interests. He is one of section editors (Systematic Review and Meta-analysis) in the Journal of Thoracic Disease. He also acts as a forum moderator in http://i.dxy.cn/profile/200750383. FW is an anesthetist, and he has published more than 10 papers in peer-reviewed journals such as Chest, Critical Care and American Journal of Emergency Medicine. JB is a professor of medicine and vice-chair of the Department of Intensive Care Adults at Erasmus Medical Centre in Rotterdam, the Netherlands, and is a professor of medicine at the Pontificia Universidad Católica de Chile. He is also currently a visiting professor at Columbia University Medical Center-New York Presbyterian Hospital in New York City. He has published over 160 articles and edited 19 books, and he has made presentations at more than 450 conferences. He is the editor of Intensive Care Medicine and Netherlands Journal of Critical Care. He is a member of the editorial boards of Reista Brasileira de Terapia Intensivia (Brasil), the Turkish Journal of Anaesthesiology and Reanimation, Journal of Critical Care and ICU Management. He is former treasurer and president of the Dutch Society of Intensive Care and currently is a member of the organizing committee of the annual International Symposium on Intensive Care and Emergency Medicine in Brussels, Belgium. He has organized a 5-day workshop on intensive care annually for 11 years and annual meetings for ICU nurses for the past 9 years. LT is a nurse anesthetist. JCL is a professor of anaesthesiology and acts as the Director of the Department of Anaesthesiology in the First Affiliated Hospital of Guangxi Medical University.

\section{Author details}

'Department of Anaesthesiology, the First Affiliated Hospital, Guangxi Medical University, 22 Shuangyong Road, Nanning 530021, China.

2Department of Anaesthesiology, General Hospital of Jinan Military Command, 25 Shifan Road, Jinan 250031, China. ${ }^{3}$ Department of Intensive Care Adults, Erasmus MC University Medical Centre, PO Box 2040, 3000 Rotterdam, CA, the Netherlands.

Received: 30 May 2014 Accepted: 3 October 2014

Published online: 20 October 2014 


\section{References}

1. Dellinger RP, Levy MM, Rhodes A, Annane D, Gerlach H, Opal SM, Sevransky JE, Sprung CL, Douglas IS, Jaeschke R, Osborn TM, Nunnally ME, Townsend SR, Reinhart K, Kleinpell RM, Angus DC, Deutschman CS, Machado FR, Rubenfeld GD, Webb SA, Beale RJ, Vincent JL, Moreno R, Surviving Sepsis Campaign Guidelines Committee including the Pediatric Subgroup: Surviving Sepsis Campaign: international guidelines for management of severe sepsis and septic shock: 2012. Crit Care Med 2013, 41:580-637.

2. Angus DC, Linde-Zwirble WT, Lidicker J, Clermont G, Carcillo J, Pinsky MR: Epidemiology of severe sepsis in the United States: analysis of incidence, outcome, and associated costs of care. Crit Care Med 2001, 29:1303-1310.

3. Annane D, Bellissant E, Cavaillon JM: Septic shock. Lancet 2005, 365:63-78.

4. Centers for Disease Control and Prevention (CDC): Current trends: increase in National Hospital Discharge Survey rates for septicemia-United States, 1979-1987. MMWR Morb Mortal Wkly Rep 1990, 39:31-34.

5. Cecconi M, Corredor C, Arulkumaran N, Abuella G, Ball J, Grounds RM, Hamilton M, Rhodes A: Clinical review: goal-directed therapy - What is the evidence in surgical patients? The effect on different risk groups. Crit Care 2013, 17:209.

6. Rivers E, Nguyen B, Havstad S, Ressler J, Muzzin A, Knoblich B, Peterson E, Tomlanovich M, Early Goal-Directed Therapy Collaborative Group: Early goal-directed therapy in the treatment of severe sepsis and septic shock. N Engl J Med 2001, 345:1368-1377.

7. ProCESS Investigators: A randomized trial of protocol-based care for early septic shock. N Engl J Med 2014, 370:1683-1693.

8. Higgins JPT, Green S (Eds): Cochrane Handbook for Systematic Reviews of Interventions (Version 5.1.0) [updated March 2011]. The Cochrane Collaboration; 2011. Available from www.cochrane-handbook.org.

9. Moher D, Liberati A, Tetzlaff J, Altman DG, PRISMA Group: Preferred reporting items for systematic reviews and meta-analyses: the PRISMA statement. BMJ 2009, 339:b2535.

10. Higgins JPT, Altman DG, Gøtzsche PC, Jüni P, Moher D, Oxman AD, Savovic J, Schulz KF, Weeks L, Sterne JA, Cochrane Bias Methods Group, Cochrane Statistical Methods Group: The Cochrane Collaboration's tool for assessing risk of bias in randomised trials. BMJ 2011, 343:d5928.

11. Higgins JPT, Thompson SG: Quantifying heterogeneity in a meta-analysis. Stat Med 2002, 21:1539-1558.

12. Higgins JPT, Thompson SG, Deeks JJ, Altman DG: Measuring inconsistency in meta-analyses. BMJ 2003, 327:557-560.

13. DerSimonian R, Laird N: Meta-analysis in clinical trials. Control Clin Trials 1986, 7:177-188.

14. Egger M, Davey Smith G, Schneider M, Minder C: Bias in meta-analysis detected by a simple, graphical test. BMJ 1997, 315:629-634.

15. Guyatt GH, Oxman AD, Vist GE, Kunz R, Falck-Ytter Y, Alonso-Coello P, Schünemann HJ, GRADE Working Group: GRADE: an emerging consensus on rating quality of evidence and strength of recommendations. BMJ 2008, 336:924-926.

16. Tuchschmidt J, Fried J, Astiz M, Rackow E: Elevation of cardiac output and oxygen delivery improves outcome in septic shock. Chest 1992, 102:216-220.

17. Yu M, Levy MM, Smith P, Takiguchi SA, Miyasaki A, Myers SA: Effect of maximizing oxygen delivery on morbidity and mortality rates in critically ill patients: a prospective, randomized, controlled study. Crit Care Med 1993, 21:830-838.

18. Hayes MA, Timmins AC, Yau EH, Palazzo M, Hinds CJ, Watson D: Elevation of systemic oxygen delivery in the treatment of critically ill patients. N Engl J Med 1994, 330:1717-1722.

19. Gattinoni L, Brazzi L, Pelosi P, Latini R, Tognoni G, Pesenti A, Fumagalli R: SvO2 Collaborative Group: A trial of goal-oriented hemodynamic therapy in critically ill patients. N Engl J Med 1995, 333:1025-1032.

20. Yu M, Burchell S, Hasaniya NW, Takanishi DM, Myers SA, Takiguchi SA: Relationship of mortality to increasing oxygen delivery in patients $\geq 50$ years of age: a prospective, randomized trial. Crit Care Med 1998, 26:1011-1019.

21. Alía I, Esteban A, Gordo F, Lorente JA, Diaz C, Rodriguez JA, Frutos F: A randomized and controlled trial of the effect of treatment aimed at maximizing oxygen delivery in patients with severe sepsis or septic shock. Chest 1999, 115:453-461.
22. Lin $\mathrm{SM}$, Huang $C D$, Lin $\mathrm{HC}$, Liu CY, Wang CH, Kuo HP: A modified goal-directed protocol improves clinical outcomes in intensive care unit patients with septic shock: a randomized controlled trial. Shock 2006, 26:551-557.

23. Wang XZ, Lü CJ, Gao FQ, Li XH, Yan WF, Ning FY: [Efficacy of goal-directed therapy in the treatment of septic shock] [Article in Chinese]. Zhongguo Wei Zhong Bing Ji Jiu Yi Xue 2006, 18:661-664.

24. Chen ZQ, Jin YH, Chen H, Fu WJ, Yang H, Wang RT: [Early goal-directed therapy lowers the incidence, severity and mortality of multiple organ dysfunction syndrome] [Article in Chinese]. Nan Fang Yi Ke Da Xue Xue Bao 2007, 27:1892-1895.

25. He ZY, Gao Y, Wang XR, Hang YN: [Clinical evaluation of execution of early goal directed therapy in septic shock] [Article in Chinese]. Zhongguo Wei Zhong Bing Ji Jiu Yi Xue 2007, 19:14-16.

26. Early Goal-Directed Therapy Collaborative Group of Zhejiang Province: [The effect of early goal-directed therapy on treatment of critical patients with severe sepsis/septic shock: a multi-center, prospective, randomized, controlled study] [Article in Chinese]. Zhongguo Wei Zhong Bing Ji Jiu Yi Xue 2010, 22:331-334.

27. Wira CR, Dodge K, Sather J, Dziura J: Meta-analysis of protocolized goal-directed hemodynamic optimization for the management of severe sepsis and septic shock in the emergency department. West J Emerg Med 2014, 15:51-59.

28. Jones AE, Shapiro NI, Trzeciak S, Arnold RC, Claremont HA, Kline JA, Emergency Medicine Shock Research Network (EMShockNet) Investigators: Lactate clearance vs central venous oxygen saturation as goals of early sepsis therapy: a randomized clinical trial. JAMA 2010, 303:739-746.

29. Jansen TC, van Bommel J, Schoonderbeek FJ, Sleeswijk Visser SJ, van der Klooster JM, Lima AP, Willemsen SP, Bakker J, LACTATE study group: Early lactate-guided therapy in intensive care unit patients: a multicenter, open-label, randomized controlled trial. Am J Respir Crit Care Med 2010, 182:752-761.

30. Legrand M, Dupuis C, Simon C, Gayat E, Mateo J, Lukaszewicz AC, Payen D: Association between systemic hemodynamics and septic acute kidney injury in critically ill patients: a retrospective observational study. Crit Care 2013, 17:R278.

31. The ProCESS/ARISE/ProMISe Methodology Writing Committee: Harmonizing international trials of early goal-directed resuscitation for severe sepsis and septic shock: methodology of ProCESS, ARISE, and ProMISe. Intensive Care Med 2013, 39:1760-1775.

doi:10.1186/s13054-014-0570-5

Cite this article as: Gu et al:: The effect of goal-directed therapy on mortality in patients with sepsis - earlier is better: a meta-analysis of randomized controlled trials. Critical Care 2014 18:570.

\section{Submit your next manuscript to BioMed Central and take full advantage of:}

- Convenient online submission

- Thorough peer review

- No space constraints or color figure charges

- Immediate publication on acceptance

- Inclusion in PubMed, CAS, Scopus and Google Scholar

- Research which is freely available for redistribution

Submit your manuscript at www.biomedcentral.com/submit
C Biomed Central 